\title{
Physical, Structural, and Magnetic Study of Dilute Magnetic Glasses: $x \mathrm{Fe}_{2} \mathrm{O}_{3}+(2-x) \mathrm{V}_{2} \mathrm{O}_{5}+38 \mathrm{Li}_{2} \mathrm{O}+60 \mathrm{P}_{2} \mathrm{O}_{5}$
}

\author{
P. $\mathrm{CHAND}^{a, *}, \mathrm{~L} . \mathrm{KUMAR}^{a}$ AND S. KhasA ${ }^{b}$
}

${ }^{a}$ Material Science, Department of Physics, SRM University, Delhi-NCR Sonepat-131029, Haryana, India

${ }^{b}$ Materials Research Laboratory, Department of Physics, DCR University of Science and Technology,

Sonepat-131039, Haryana, India

(Received March 8, 2020; in final form April 6, 2020)

Dilute magnetic glasses of formula $x \mathrm{Fe}_{2} \mathrm{O}_{3}+(2-x) \mathrm{V}_{2} \mathrm{O}_{5}+38 \mathrm{Li}_{2} \mathrm{O}+60 \mathrm{P}_{2} \mathrm{O}_{5}$ (where $x=0,0.2,0.5,0.7,1.0$, 1.5 and 2.0) are synthesized by melt quench technique. The glassy nature is confirmed by X-ray diffraction. The density is found to increase but the molar volume and optical basicity are found to decrease as the iron content $x$ is gradually increased from 0 to up to 2 . The Fourier transform infrared spectra of these glasses show absorption peaks corresponding to $\mathrm{P}=\mathrm{O}$, O-P-O-, $(\mathrm{P}-\mathrm{O}-\mathrm{P})$ symmetric stretching, $(\mathrm{P}-\mathrm{O}-\mathrm{P})$ asymmetric stretching, and $\mathrm{O}-\mathrm{P}-\mathrm{O}$ group bending vibrations. The magnetic measurements indicate considerable reduction in magnetization of both vanadium and iron containing glasses. A canted-antiferromagnetic pairing of the magnetic ion pairs is envisaged for explaining the reduction of magnetization. The EPR spectra reveal the presence of vanadyl ion and ferric ion in the glasses. Characteristics of local bonding and co-ordination of vanadyl and ferric ions are discussed. The vanadyl ion is shown to have a distorted octahedral coordination with oxygen to create a tetragonal contraction. The high spin ferric ion is concluded to possess two kinds of co-ordinations with oxygen viz. rhombic and octahedral in these glasses. The effects of magnetic exchange on the EPR features are discussed.

DOI: 10.12693/APhysPolA.137.1196

PACS/topics: dilute magnetic glasses, phosphate glasses, EPR, FTIR, magnetization, vanadyl, iron

\section{Introduction}

Ever growing developments that demonstrate the importance, versatility, and promise of glasses for newer and newer uses make these materials very attractive for research. Glass is an immensely versatile material since it is used every day in numerous applications and side by side there are more specific technological applications in various fields of science and technology. The chemical formulation dictates the physical properties and characteristics of the glass [1]. Phosphate glasses are mainly composed of the network former $\mathrm{P}_{2} \mathrm{O}_{5}$, i.e., $\mathrm{P}^{5+}$ and $\mathrm{O}^{2+}$. The phosphate glasses feature a high resistance to hydrofluoric acid, but otherwise they have a relatively low resistance to chemical corrosion. The compositions can be made more resistant to the chemicals and the environment by engineering the composition for the specific applications.

Phosphate glasses are well suited for doping with various colorants, including transition metal ions and rare earth oxides [2]. This ability results in glasses that exhibit unique and desirable transmission spectrum. These coloured glasses have found their niche in various medical, military, and scientific applications. Bioactive glass, which is the material of choice to promote bone growth in the medical industry, is also a phosphate-based

*corresponding author; e-mail: satyam20@gmail.com glass [3-5]. The glasses are prepared by almost limitless different chemical compositions, which in turn give rise to different properties.

Phosphate glasses generally have lower manufacturing temperature, lower glass transition temperature, lower dispersion, and higher refractive index as compared to silicate-based optical glasses. Thus, phosphate glasses offer a greater advantage in many applications, such as moulding of optical elements, and nuclear waste storage. Phosphate glasses have gained recent interest due to their potential applications as solid-state amorphous electrolytes in secondary batteries.

Recent results indicate that it is possible to prepare phosphate glasses with excellent resistance to aqueous corrosion by adding metal oxides with high valence cations like $\mathrm{Fe}_{2} \mathrm{O}_{3}, \mathrm{Al}_{2} \mathrm{O}_{3}$, and $\mathrm{V}_{2} \mathrm{O}_{5}$. Also, $\mathrm{V}_{2} \mathrm{O}_{5}$ is known to participate in the glass network with $\mathrm{VO}_{5}$ pyramidal structural units or $\mathrm{VO}_{6}$ octahedral structural units. Therefore the $\left[\mathrm{PO}_{4}\right]$ tetrahedral structural units, gets modified to different units in the alkali phosphate glasses. Vanadium can exist in various oxidation states (such as $\mathrm{V}^{5+}, \mathrm{V}^{4+}, \mathrm{V}^{3+}$ and $\mathrm{V}^{2+}$ ) by bonding with different number of oxygen atoms. Out of which only $\mathrm{V}^{5+}$ is non-magnetic [6, 7]. Also, it is well known that iron exists in two oxidation states: $\mathrm{Fe}(\mathrm{II})\left(3 d^{4}\right)$ and/or $\mathrm{Fe}(\mathrm{III})\left(3 d^{5}\right)$, and both of them are strongly magnetic in nature in their high spin state. The magnetic behaviour of these ions can be studied by electron paramagnetic resonance (EPR) spectroscopy [6-9], and magnetization measurements by vibrating sample magnetometer (VSM) [10, 11]. The EPR of Fe(II) is not observed at 
room temperature (RT) and can rarely be detected at very low temperatures. However, Fe(III) is EPR active even at RT and above [12]. Vanadium oxidation states $\left(\mathrm{V}^{2+}, \mathrm{V}^{3+}, \mathrm{V}^{4+}\right)$ can be identified through their characteristic EPR spectra [13-15]. The oxidation state $\mathrm{V}^{4+}$ bonds with oxygen to form a distinct $(\mathrm{V}=\mathrm{O})$ bond known as vanadyl ion $(\mathrm{VO})^{2+}\left(3 d^{1}\right)$ whose EPR is very distinct in solutions, powders, glasses and crystals [16, 17]. Therefore, the magnetic behaviour of the glasses containing both iron and vanadium oxides would be interesting to study by EPR and VSM.

Structural information is usually obtained by XRD and FTIR spectroscopy. Garbarczyk et al. have studied $\mathrm{Li}_{2} \mathrm{O}-\mathrm{V}_{2} \mathrm{O}_{5}-\mathrm{P}_{2} \mathrm{O}_{5}$ glasses by differential scanning calorimetry (DSC), EPR and impedance spectroscopy [18]. The nature of electronic conductivity in olivine-like glasses and nanomaterials of $\mathrm{Li}_{2} \mathrm{O}-\mathrm{FeO}-\mathrm{V}_{2} \mathrm{O}_{5}-\mathrm{P}_{2} \mathrm{O}_{5}$ system have been studied by Pietrzak et al [19]. The authors have recently published a paper on the structural, physical, electrical and dielectric properties of dilute magnetic glasses: $x \mathrm{Fe}_{2} \mathrm{O}_{3}+(30-x) \mathrm{V}_{2} \mathrm{O}_{5}+30 \mathrm{Na}_{2} \mathrm{O}+40 \mathrm{~B}_{2} \mathrm{O}_{3}$ (with $x=0$ to 15 ) [20]. The present investigation is aimed at the study of physical, structural, and magnetic behaviour of the dilute magnetic phosphate glasses: $x \mathrm{Fe}_{2} \mathrm{O}_{3}-(2-x) \mathrm{V}_{2} \mathrm{O}_{5}-38 \mathrm{Li}_{2} \mathrm{O}-60 \mathrm{P}_{2} \mathrm{O}_{5}$, where $x=0$, $0.2,0.5,0.7,1.0,1.5$ and 2.0 containing two magnetic ions namely iron and vanadium in different compositions. We here report results of density, molar volume, theoretical optical basicity, XRD, FTIR, VSM and EPR investigations of these glasses.

\section{Experimental}

\subsection{Glass preparation}

The glasses of the desired composition were prepared by the conventional rapid melt quenching technique. The starting materials were analytical grade reagents (ANALR): $\mathrm{NH}_{4} \mathrm{H}_{2} \mathrm{PO}_{4}, \mathrm{Li}_{2} \mathrm{CO}_{3}$, $\mathrm{V}_{2} \mathrm{O}_{5}$ and $\mathrm{Fe}_{2} \mathrm{O}_{3}$. The desired amounts of components were calculated according to the molar formula $x \mathrm{Fe}_{2} \mathrm{O}_{3}-(2-x) \mathrm{V}_{2} \mathrm{O}_{5}-38 \mathrm{Li}_{2} \mathrm{O}-60 \mathrm{P}_{2} \mathrm{O}_{5}$, where $x=0$, $0.2,0.5,0.7,1.0,1.5$ and 2.0 (abbreviated as FVLP $x$ ). The calculated amounts of the desired components were well dry mixed and homogenized. The homogenized powders were melted in high purity alumina crucibles at a temperature of $1050{ }^{\circ} \mathrm{C}$ in an electrically heated and temperature-controlled muffle furnace for about one hour. The alumina crucibles containing glass melts were swirled frequently to insure the homogeneity of the melt. The melts were then quickly quenched to lower temperature $\left(\approx 300^{\circ} \mathrm{C}\right)$ by pouring onto clean thick stainless steel (SS) plates preheated to $\approx 300^{\circ} \mathrm{C}$ and subsequently pressing by another thick SS plate which was pre heated to $\approx 300^{\circ} \mathrm{C}$ to provide a better quenching rate and to reduce the strains during glass formation. By this method smooth surfaces of the plate-glass samples were obtained upon cooling slowly to RT.

\section{2. $X R D$}

The as prepared samples were crushed to fine powders and analysed by X-ray diffractometer (Rigaku Ultima IV) by employing $\mathrm{Cu} K_{\alpha}$ radiations with nickel filter. The diffraction patterns were obtained for $2 \theta$ from $20^{\circ}$ to $80^{\circ}$ at a scan rate of $2^{\circ}$ per min.

\subsection{Density measurement}

The density $(D)$ of the prepared glass samples was measured using the Archimedes principle at RT. The masses of the samples were measured by sensitive electronic balance (CAS CAVY 220). Xylene was used as an inert immersion liquid for measuring the buoyancy. The density was calculated using the formula

$$
D=D_{\chi} \frac{W_{a}}{\left(W_{a}-W_{\chi}\right)},
$$

where $D_{\chi}, W_{a}$ and $W_{\chi}$ are density of xylene, weight of sample in air and weight of sample in buoyant liquid (here xylene), respectively. The molar volume $V_{m}$ of each glass sample was calculated from data obtained for density using formula $V_{m}=M / D$, where $M$ is molar mass of samples. The error in the density measurement was $\pm 0.01 \mathrm{~g} / \mathrm{cm}^{3}$.

The theoretical optical basicity $\left(\Lambda_{\mathrm{th}}\right)$ was calculated by using the following relation:

$$
\begin{gathered}
\Lambda_{\mathrm{th}}=X_{\mathrm{Fe}_{2} \mathrm{O}_{3}} \Lambda_{\mathrm{Fe}_{2} \mathrm{O}_{3}}+X_{\mathrm{V}_{2} \mathrm{O}_{5}} \Lambda_{\mathrm{V}_{2} \mathrm{O}_{5}} \\
+X_{\mathrm{Na}_{2} \mathrm{O}} \Lambda_{\mathrm{Na}_{2} \mathrm{O}}+X_{\mathrm{B}_{2} \mathrm{O}_{3}} \Lambda_{\mathrm{B}_{2} \mathrm{O}_{3}} .
\end{gathered}
$$

Here $X$-terms are mole fractions and $\Lambda$-terms are optical basicity values of corresponding oxides as assigned in literature.

\subsection{FTIR}

The FTIR spectra of the glass samples were recorded at RT on Perkin Elmer Frontier FTIR spectrometer in the mid-IR range $\left(400-4000 \mathrm{~cm}^{-1}\right)$. To record the infrared absorption spectra, $\mathrm{KBr}$ pellet technique was used. Base line and noise correction were achieved using Spectrum-10 software (provided with FTIR spectrophotometer). For peak identification of the processed spectra, multiple peaks fitting of each spectrum was done using Origin-16 Pro till the fit parameter became $\geq 0.999$.

\subsection{VSM measurements}

The magnetic moment as a function of applied field was measured for the prepared glasses on a vibrating sample magnetometer (VSM, Lakeshore VSM 7410) within the magnetic range $\pm 1.5 \mathrm{~T}$ with a time constant of $1 \mathrm{~s}$ and sensitivity $10^{-7} \mathrm{emu}$, at RT.

\subsection{EPR spectroscopy}

EPR measurements at RT were performed on the X-band EPR spectrometer (JEOL Model JES FA200) at X-band frequency $(\approx 9.4 \mathrm{GHz})$ and a magnetic field modulation of $100 \mathrm{kHz}$. Microwave power 
of $\approx 1 \mathrm{~mW}$ was used for EPR measurements. The amplitude of the magnetic field modulation was kept about one milli-gauss and first derivative of the resonance absorption was obtained against the DC magnetic field sweep in the desired range.

\section{Results and discussion}

\section{1. $X R D$}

The glass samples were analysed by XRD to confirm the glassy nature of the samples prepared. The XRD patterns are shown in Fig. 1. All the samples have shown only characteristic glass XRD patterns. No crystalline phase is detected by XRD. This confirms the noncrystalline nature (amorphous nature) of the samples prepared for study.

\subsection{Density}

Measured values of density $(D)$ and calculated values of molar volume $V_{M}$ are displayed in Fig. 2a. There is a slight variation in the densities of the glasses depending on the iron and vanadium contents. As can be seen, the overall change in density is around $0.04 \mathrm{~g} / \mathrm{cm}^{3}$ by replacing $\mathrm{V}_{2} \mathrm{O}_{5}$ with increasing concentration of $\mathrm{Fe}_{2} \mathrm{O}_{3}$ (from $x=0$ to $x=2$ ). The increase in density and decrease in molar volume with the increase in iron content is justified because glass modifier $\mathrm{V}$ is being replaced by heavier metal iron and a better filling factor is created by $\mathrm{Fe}-\mathrm{O}$ coordination as compared to $\mathrm{V}-\mathrm{O}$ in the glass network. The variation of density $D$, molar volume $V_{M}$ and theoretical optical basicity against the iron content $x$ are shown in Fig. $2 \mathrm{a}$ and $\mathrm{b}$.

The molar volume $V_{M}$ is found to decrease with the partial replacement of $\mathrm{V}_{2} \mathrm{O}_{5}$ by $\mathrm{Fe}_{2} \mathrm{O}_{3}$. This is in conformity with the compaction of the glass network caused by the partial introduction of $\mathrm{Fe}_{2} \mathrm{O}_{3}$ in the glass structure.

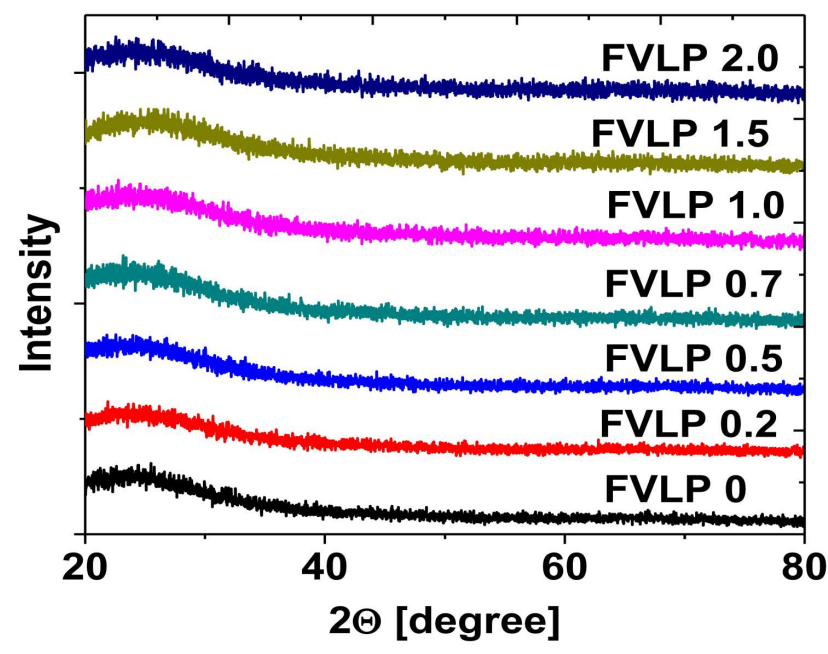

Fig. 1. XRD spectra of FVLP $x(x=0,0.2,0.5,0.7$, 1.0, 1.5 and 2.0) glasses recorded at RT.
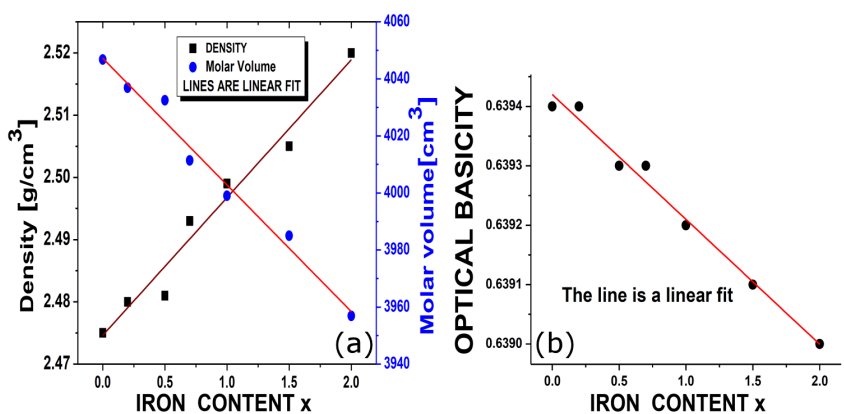

Fig. 2. (a) Variation of density $\rho$ and molar volume $V_{M}$ of FVLP $x$ glasses against iron content $x$. (b) Variation of theoretical optical basicity $\Lambda_{\mathrm{th}}$ of FVLP $x$ glasses against iron content $x$.

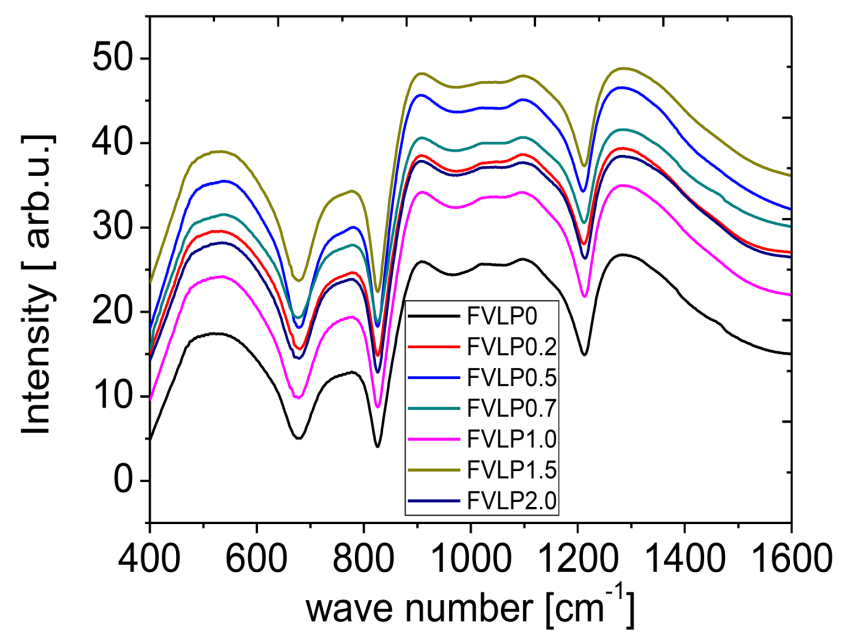

Fig. 3. FTIR spectra of FVLP $x(x=0,0.2,0.5,0.7$, $1.0,1.5$ and 2.0) glasses recorded at RT. The arrows show the principal IR absorption bands.

The optical basicity proposed by Duffy and Ingram [21] is conventionally used as a measure of acid-base properties of oxide glasses and is expressed in terms of the electron density carried by oxygen. The variation of theoretical optical basicity for the prepared compositions (as shown in Fig. 2b) shows a marginal decrease with an increase in $\mathrm{Fe}_{2} \mathrm{O}_{3}$ content at the cost of $\mathrm{V}_{2} \mathrm{O}_{5}$ in the glass. The decrease in optical basicity upon partial replacing of $\mathrm{V}_{2} \mathrm{O}_{5}$ by $\mathrm{Fe}_{2} \mathrm{O}_{3}$ indicates a decrease in the ability of glass to donate negative charge to the probe ion. It points out towards a marginal increase in covalent character of the glass network with the increase in $\mathrm{Fe}_{2} \mathrm{O}_{3}$ content.

\subsection{Infrared absorption spectra}

The Fourier transform infrared (FTIR) absorption spectra of FVLP $x$ glasses at RT and in the frequency range of $400-1600 \mathrm{~cm}^{-1}$ are shown in Fig. 3. The main absorption band positions and their assignments are given in Table I. 
TABLE I

The observed IR absorption band positions and their assignments

\begin{tabular}{c|c}
\hline \hline $\begin{array}{c}\text { Approximate band } \\
\text { position }\left[\mathrm{cm}^{-1}\right]\end{array}$ & Band assignment \\
\hline 506 & bending of $\mathrm{O}-\mathrm{P}-\mathrm{O}$ \\
\hline 641 & $\begin{array}{l}\text { symmetric stretching } \\
\text { vibration of } \mathrm{P}-\mathrm{O}-\mathrm{P} \text { linkage }\end{array}$ \\
\hline 743 & $\begin{array}{l}\text { symmetric stretching } \\
\text { vibration of } \mathrm{P}-\mathrm{O}-\mathrm{P} \text { linkage }\end{array}$ \\
\hline 881 & $\begin{array}{l}\text { asymmetric stretching } \\
\text { vibration of } \mathrm{P}-\mathrm{O}-\mathrm{P} \text { linkage }\end{array}$ \\
\hline 1012 & $\begin{array}{l}\text { PO } \mathrm{O}_{2}^{-} \text {asymmetric } \\
\text { stretching vibration }\end{array}$ \\
\hline 1126 & symmetric $\mathrm{P}-\mathrm{O}$ bonds \\
\hline 1295 & $\begin{array}{l}\text { stretching vibration } \\
\text { mode of the } \mathrm{P}=\mathrm{O}\end{array}$ \\
\hline
\end{tabular}

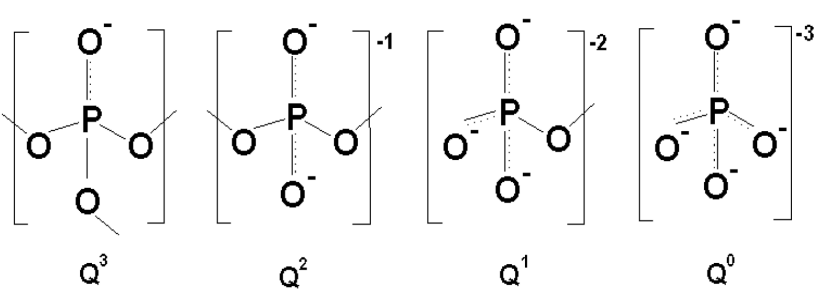

Fig. 4. Different models of phosphate tetrahedra that can exist in phosphate glasses.

The structures of phosphate anions can be described using the $Q^{n}$ terminology, where $n$ represents the number of bridging oxygens (BOs) per $\left[\mathrm{O}=\mathrm{PO}_{3}\right]$ tetrahedron as shown in Fig. 4.

Van Wazer [22] developed relationships that describe the compositional dependences of the tetrahedral site distributions in binary alkali phosphate glasses. The addition of a modifying oxide $\left(\mathrm{M}_{2} \mathrm{O}\right)$ to phosphate glass depolymerises the structure from those with more highly cross linked tetrahedral units to those with more nonbridging oxygen (NBOs) units to maintain charge balance as shown below

$$
\begin{aligned}
& {\left[2 Q^{3}+\mathrm{M}_{2} \mathrm{O}\right] \rightarrow 2 Q^{2}, \quad\left[2 Q^{2}+\mathrm{M}_{2} \mathrm{O}\right] \rightarrow 2 Q^{1},} \\
& {\left[2 Q^{1}+\mathrm{M}_{2} \mathrm{O}\right] \rightarrow 2 Q^{0} .}
\end{aligned}
$$

The $\mathrm{Li}_{2} \mathrm{O}$ breaks the $-\mathrm{P}-\mathrm{O}-\mathrm{P}$-linkage of the phosphate glass and creates more and more NBOs as the concentration is increased. Therefore, $\left[\mathrm{PO}_{4}\right],\left[\mathrm{PO}_{4}\right]^{3-}, \mathrm{O}-\mathrm{P}-\mathrm{O}$, $\mathrm{P}-\mathrm{O}-\mathrm{P}$ and $\mathrm{P}=\mathrm{O}$, etc., species are expected in lithium phosphate glasses in different populations depending on the composition [23-25]. The peaks in the region $1300-1200 \mathrm{~cm}^{-1}$ are assigned to the stretching vibration modes of the $\mathrm{P}=\mathrm{O}$.

Intensity of bands at $\approx 1300 \mathrm{~cm}^{-1}$ strongly depends on phosphate content. There are at least two bands in this region which are clearly seen in Fig. 3. These two bands are connected with $\mathrm{P}=\mathrm{O}$ vibrations affected by asym- metric stretching vibrations of $\mathrm{O}-\mathrm{P}-\mathrm{O}$ bonds. Position of these bands strongly depends on the chemical composition of the glass. The band at $\approx 1100 \mathrm{~cm}^{-1}$ results from symmetric $\mathrm{O}-\mathrm{P}-\mathrm{O}$ vibrations in phosphate tetrahedral units. The band at $\approx 1020 \mathrm{~cm}^{-1}$ is connected with $\mathrm{PO}_{2}^{-}$asymmetric stretching vibrations. The absorption band at $889-879 \mathrm{~cm}^{-1}$ is attributed to asymmetric stretching vibrations of $\mathrm{P}-\mathrm{O}-\mathrm{P}$ linkage of $Q^{1}$ tetrahedral units with NBO. The band around $850-600 \mathrm{~cm}^{-1}$, may be attributed to the symmetric stretching vibration of $\mathrm{P}-\mathrm{O}-\mathrm{P}$ linkage of $Q^{2}$ tetrahedral units with NBO. The spectra exhibit a strong broad absorption peak in the region $506-474 \mathrm{~cm}^{-1}$, which is attributed to the $\mathrm{O}-\mathrm{P}-\mathrm{O}$ bending modes [23-25]. It may also be noted that in the region $800-1300 \mathrm{~cm}^{-1}$ the spectra show some band splitting suggesting minor structural modifications due to vanadium/iron inclusion in the glasses. The FTIR spectra show the characteristic peaks originating from the phosphate network and all the glasses under study show essentially the similar spectra. This means that iron and vanadium are entering in the glass network as glass formers in the range of concentrations used in this study (up to 2 mol fraction of $\mathrm{Fe}_{2} \mathrm{O}_{3}$ ).

\subsection{Magnetization measurements}

The magnetization $[\mathrm{emu} / \mathrm{g}]$ versus magnetic field $H[\mathrm{G}]$ at RT is shown in Fig. 5. The magnetization curves did not show any hysteresis and were linear. These are the characteristics of the paramagnetic materials. The magnetic data obtained from the analysis of magnetization curves for all the samples are given in Table II for comparison.

The magnetization in FVNB0 is due to vanadium only since no iron is present in this sample. The vanadium atom can exist in $\mathrm{V}^{2+}, \mathrm{V}^{3+}, \mathrm{V}^{4+}$ and $\mathrm{V}^{5+}$ oxidation states out of which only $\mathrm{V}^{5+}$ is non-magnetic and hence EPR silent. The $\mathrm{V}^{2+}, \mathrm{V}^{3+}$ and $\mathrm{V}^{4+}$ oxidation states

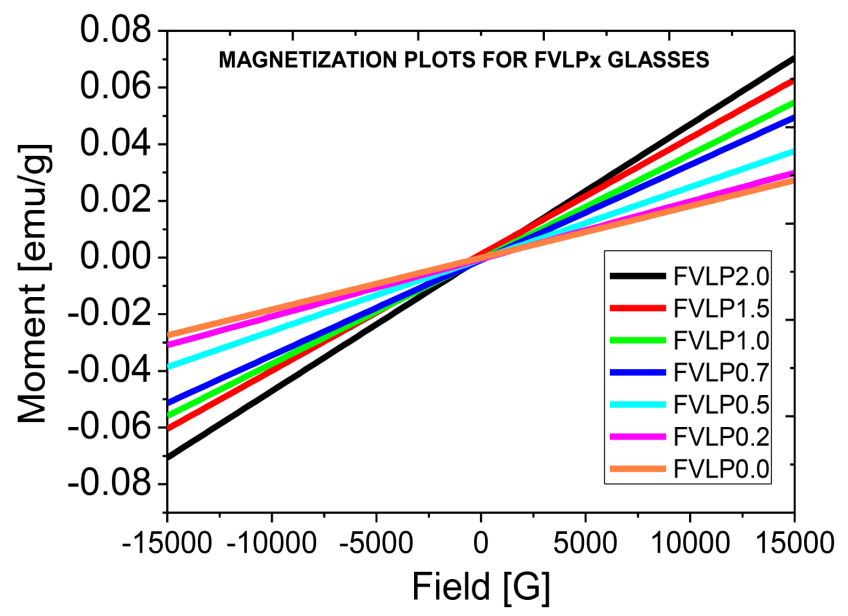

Fig. 5. The magnetization $M-H$ curves of the FVLP $x$ glasses between $\pm 15 \mathrm{kG}$ and at RT. 
Magnetic data obtained from the analysis of $M-H$ plots of FVLP $x$ glasses at RT.

\begin{tabular}{c|c|c|c|c|c|c|c|c}
\hline \hline Sample & $\begin{array}{c}M \text { at } 15 \mathrm{kG} \\
\times 10^{-2}[\mathrm{emu} / \mathrm{g}]\end{array}$ & $\begin{array}{c}M_{\mathrm{fu}} \text { at } 15 \mathrm{kG} \\
{[\mathrm{emu}]}\end{array}$ & $\begin{array}{c}\chi=M / H \times 10^{-6} \\
{[\mathrm{emu} / \mathrm{g}-\mathrm{G}]}\end{array}$ & $\begin{array}{c}\left(\mu_{\mathrm{exp}}\right)_{\mathrm{fu}} \\
{[\mathrm{BM}]}\end{array}$ & $\begin{array}{c}\left(\mu_{\mathrm{th}}\right)_{\mathrm{fu}} \\
{[\mathrm{BM}]}\end{array}$ & $\begin{array}{c}\left(\mu_{\mathrm{exp}}\right)[\mathrm{BM}] \\
\mathrm{V} \text { or Fe }\end{array}$ & $\begin{array}{c}\left(\mu_{\mathrm{th}}\right) \\
\mathrm{V} \text { or Fe }\end{array}$ & $\begin{array}{c}\left(\mu_{\mathrm{pair}}\right)[\mathrm{BM}] \\
\text { and } \phi\left[{ }^{\circ}\right]\end{array}$ \\
\hline FVLP0.0 & 2.73 & 4.72 & 1.82 & 6.59 & 6.92 & 1.65 per $\mathrm{V}$ & $1.73 / \mathrm{V}^{4+}$ & \\
FVLP0.2 & 3.00 & 5.18 & 2.00 & 6.91 & 8.43 & & & \\
FVLP0.5 & 3.76 & 6.50 & 2.51 & 7.74 & 10.69 & & \\
FVLP0.7 & 4.95 & 8.56 & 3.30 & 8.87 & 12.20 & & & \\
FVLP1.0 & 5.48 & 9.47 & 3.65 & 9.33 & 14.46 & & & \\
FVLP1.5 & 6.28 & 10.84 & 4.19 & 9.99 & 18.23 & & & \\
FVLP2.0 & 7.05 & 12.17 & 4.70 & 10.57 & 22.00 & 2.64 per Fe & $5.5 / \mathrm{Fe}^{3+}$ & $5.28 ; \phi=58.7$
\end{tabular}

are EPR active and can be identified by their characteristic EPR spectra. Magnetization curve cannot resolve the issue of existing vanadium oxidation states. In this regard complementary information can be obtained by EPR of this sample. As will be discussed in the EPR results the main paramagnetic species is believed to be $\mathrm{V}^{4+}$. Therefore, magnetization is believed mainly to be due to $\mathrm{V}^{4+}$. However, the measured value of magnetisation indicates that only about $12 \%$ of the total vanadium exists in $\left(\mathrm{V}^{4+}\right)$ magnetic state, so the diamagnetic contribution has not been taken into account into the analysis.

A similar observation was reported by Mekki et al. in vanadium-sodium silicate glasses where only $2 \%$ of total vanadium was found in $\mathrm{V}^{4+}$ oxidation state and most of it lied in the non-magnetic $\mathrm{V}^{5+}$ oxidation state [26]. Similar observation was reported by Saetova et al. [27] in $\mathrm{Li}_{2} \mathrm{O}-\mathrm{V}_{2} \mathrm{O}_{5}-\mathrm{B}_{2} \mathrm{O}_{3}$ glasses. Alternatively, if the other possibility is accepted that all the vanadium exists in magnetic state $\mathrm{V}^{4+}$ and there exists a magnetic exchange interaction between the $\mathrm{V}^{4+}-\mathrm{V}^{4+}$ pairs resulting in a canted antiferromagnetic (CAFM) coupling of the magnetic moments giving rise to $\mu_{\mathrm{eff}}=\left(\mu_{A}-\mu_{B} \cos (\varphi)\right)$, where $\mu_{A}=\mu_{\mathrm{B}}$, i.e., $\left(\mu_{\mathrm{V}}^{4+}=1.73 \mathrm{BM}\right)$ and $\varphi$ is the angle between the CAFM coupled magnetic momenta $\mu_{A}$ and $\mu_{\mathrm{B}}$. The $\mu_{\mathrm{eff}}$ is the resultant magnetic moment of the coupled pair. Magnetic exchange coupling between different magnetic ion pairs was suggested by Ardelean et al. [28] in $\mathrm{Bi}_{2} \mathrm{O}_{3}-\mathrm{GeO}_{2}$ magnetic glasses to cause reduction in observed magnetization. If the canting angle $\varphi$ is close to zero the resultant magnetic moment will be very small. In the case of FVNB0 canting angle is estimated to be $\approx 41^{\circ}$ that means two $\mathrm{V}^{4+}$ magnetic dipoles $(\mu=1.73 \mathrm{BM})$ are coupled antiferromagnetically with a canting angle of $41^{\circ}$ degree resulting in an effective magnetic moment $\left(\mu_{\mathrm{eff}}=0.44 \mathrm{BM}\right)$ per pair in agreement with the experimental value. Before discussing other results, it is convenient to examine the results on FVLP2.0 glass which contains only iron content because the vanadium content is zero. Here the magnetization results due to iron which can exist in $\mathrm{Fe}^{2+}$ and/or $\mathrm{Fe}^{3+}$. Both the oxidation states are magnetic but only $\mathrm{Fe}^{3+}$ is EPR active at RT and above $[10,13]$.

The observed EPR of FVLP2.0 confirms the presence of $\mathrm{Fe}^{3+}$ oxidation state of iron in the glass but does not rule out the presence of $\mathrm{Fe}^{2+}$ in the glass under discussion. However, both $\mathrm{Fe}^{+2}(\mu \approx 5 \mathrm{BM})$ and $\mathrm{Fe}^{3+}$ $(\mu \approx 5.5 \mathrm{BM})$ have much higher atomic magnetic moments in their high spin state as compared to $\mathrm{V}^{4+}$. Assuming that all the iron exists in $\mathrm{Fe}^{3+}$ high spin state and the diamagnetic contribution is ignored, the theoretical magnetic moment per formula unit [fu] comes out to be $22 \mathrm{BM}$. The experimental value comes out to be only $1.38 \mathrm{BM}$ which is one order of magnitude lower. It amounts to only $\approx 6.3 \%$ of total Fe atoms are contributing to magnetization. Assuming the presence of both $\mathrm{Fe}^{2+}$ and $\mathrm{Fe}^{3+}$ and considering even diamagnetic contributions, the discrepancy in the theoretical and experimental results is not resolved. Therefore, the alternative explanation suggested for vanadium above CAFM may be used here assuming the $\mathrm{Fe}^{3+}-\mathrm{Fe}^{3+}$ coupled pairs antiferromagnetically. The estimated canting angle comes out to be $\approx 29^{\circ}$ in this case and the resultant magnetic moment per pair is estimated to be $\approx 0.69 \mathrm{BM}$ per pair which agrees well with the experimental value of 0.7 BM per pair.

From the values of magnetic moment per pair the values of magnetic moment per fu are calculated and are given as $\mu_{\text {cal }}$ in Table II for a comparison. These values are in satisfactory agreement with the $\mu_{\exp }$ values. The experimental and the calculated values of magnetic moment per formula unit ( $\mu_{\exp }$ and $\mu_{\mathrm{th}}$, respectively) are plotted in Fig. 6 and Fig. 7. It is clear that there is a great discrepancy between the expected magnetization and the experimental magnetization of the FVLP $x$ glasses and a magnetic exchange of CAFM coupling between the ion pairs is envisaged to explain the results.

\section{5. $E P R$}

The EPR spectra of all the FVLP $x$ glasses are shown in Fig. 8. These spectra can be divided into two groups. In one group there are the spectra of samples FVLP0, FVLP0.2 and FVLP0.5 where clear sharp splitting of EPR signals is discernible in the magnetic field range of $250 \mathrm{mT}$ to $450 \mathrm{mT}$ and in the other group there are the spectra of samples FVLP1.0, FVLP1.5 and FVLP2.0, where prominently structureless broad EPR signals are seen.

We shall first concentrate on the EPR spectra of the first group. The EPR spectrum of the sample FVLP0 is blown in Fig. 9 to analyse it precisely. The glass FVNB0 does not contain any iron in it, therefore EPR signals in FVLP0 should arise due to vanadium only without any 


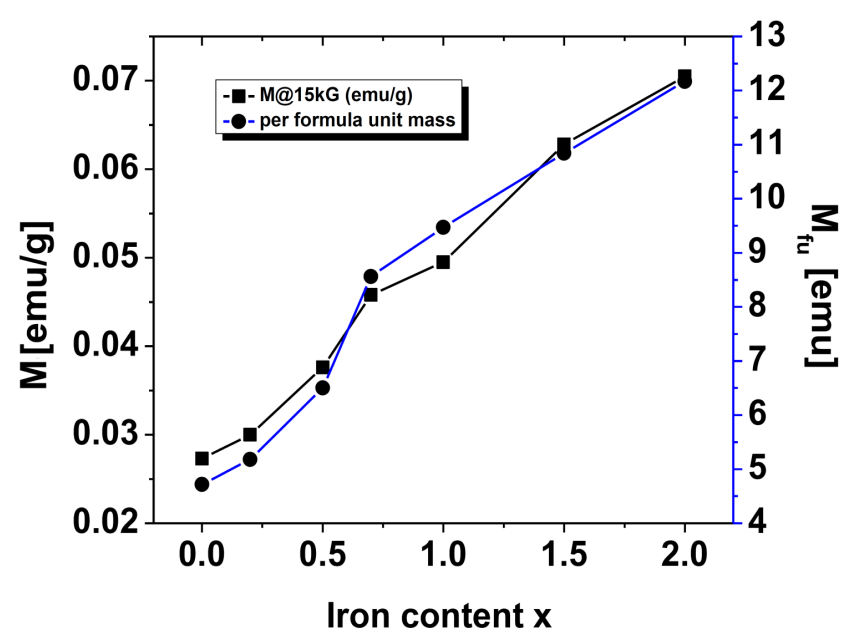

Fig. 6. Magnetization [emu/g] and [emu] per formula unit for the maximal applied magnetic field of $1.5 \mathrm{~T}$, i.e. $15 \mathrm{kG}$.

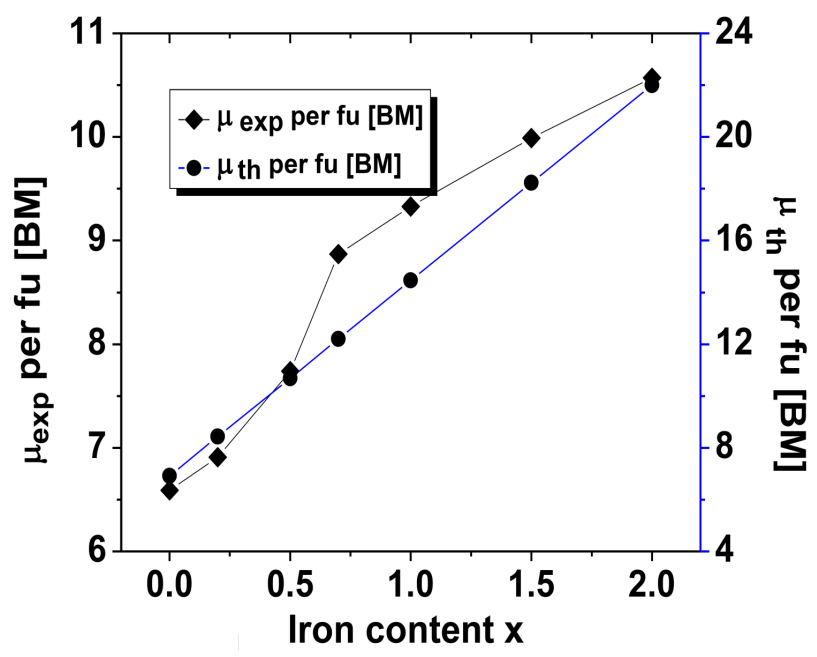

Fig. 7. $\mu_{\exp }$ per fu $[\mathrm{BM}]$ and $\mu_{t h}$ per fu $[\mathrm{BM}]$ vs. iron content $x$.

interference from other paramagnetic ions. In diamagnetic hosts sharp line $(\approx 15 \mathrm{G})$ EPR spectra of vanadium(IV) magnetic ions are observed even at RT due to the absence of magnetic dipolar broadening and magnetic exchange interaction which further reduces on lowering the temperature. Vanadium(IV) usually forms a distinct covalent bond with oxygen resulting in the vanadyl molecular ion $(\mathrm{V}=\mathrm{O})^{2+}$ whose characteristic EPR spectrum $\left(S=1 / 2, I=7 / 2\right.$ for $\left.{ }^{51} \mathrm{~V}\right)$ is easily identified by characteristic eight hyperfine lines due to nuclear spin $I=7 / 2[17,20,29,30]$. Vanadyl EPR can be easily identified in crystals, liquids, powders and glasses. In glasses a characteristic sixteen line spectrum (a combination of $\mathrm{O}=0$, i.e., the so called parallel part and $\mathrm{O}=90$, i.e., the so called perpendicular part) is obtained due to the randomly oriented $\mathrm{V}=\mathrm{O}$ bonds of vanadyl local complexes in the glass network akin to powders when no dipolar and/or exchange interactions are present [17].

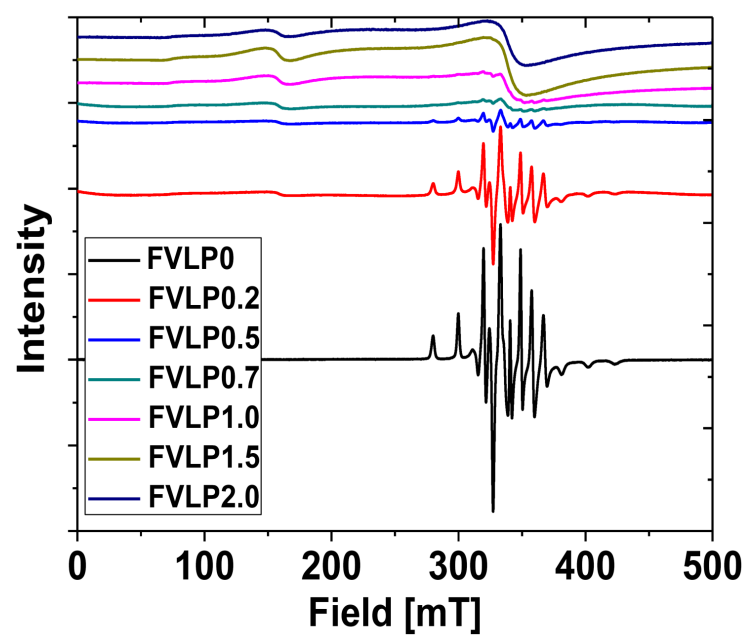

Fig. 8. EPR spectra of FVLP $x$ glasses at RT and at $\mathrm{X}$-band. The first derivative of EPR absorption signals is plotted against applied DC magnetic sweep.

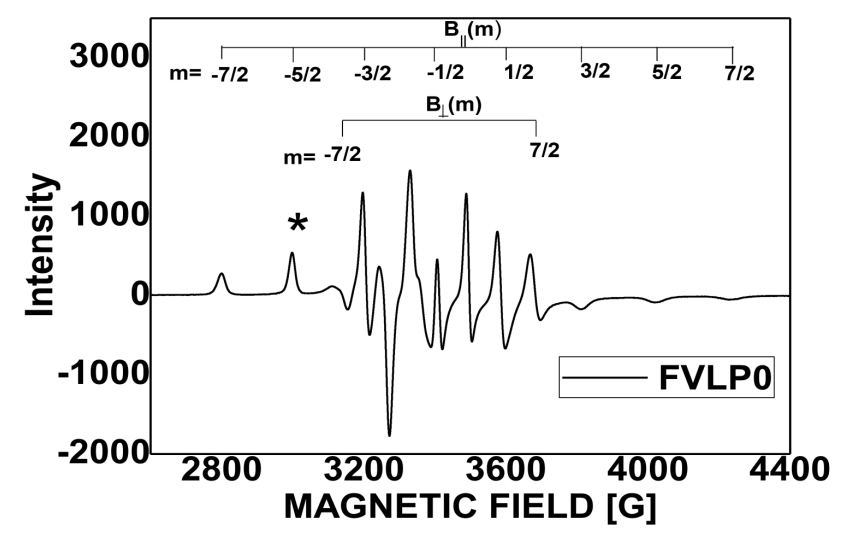

Fig. 9. EPR spectrum of FVLP0 glass at RT and Xband. The peaks of the parallel and perpendicular parts are identified by $B_{\perp}(m)$ and $B_{\|}(m)$, respectively. The peaks corresponding to marked by $*$ were used to determine the line widths in the different spectra.

Broadening or smearing of EPR spectra may occur due to magnetic exchange interactions and/or motions of the ions [31-33].

As a consequence, liquids show only averaged eight hyperfine lines and in higher concentrations of vanadium(IV) even the hyperfine structure is smeared out to give rise to a single structure less line EPR spectrum. Since the $\mathrm{V}_{2} \mathrm{O}_{5}$ content in FVNB0 is high (2 mol.\%), consequently magnetic exchange effects are expected in its EPR spectra even at RT and a structureless EPR spectrum is expected. Contrary to it, the observed EPR spectrum is well resolved hence indicates a diminished magnetic exchange interaction between the $\mathrm{V}^{4+} \mathrm{EPR}$ ion probes. Interestingly, a well resolved 8-line EPR spectrum was reported even for the pure vanadyl complex (a dense magnetic system) at RT [31]. The reason was assigned to the reduced magnetic exchange and dipolar 


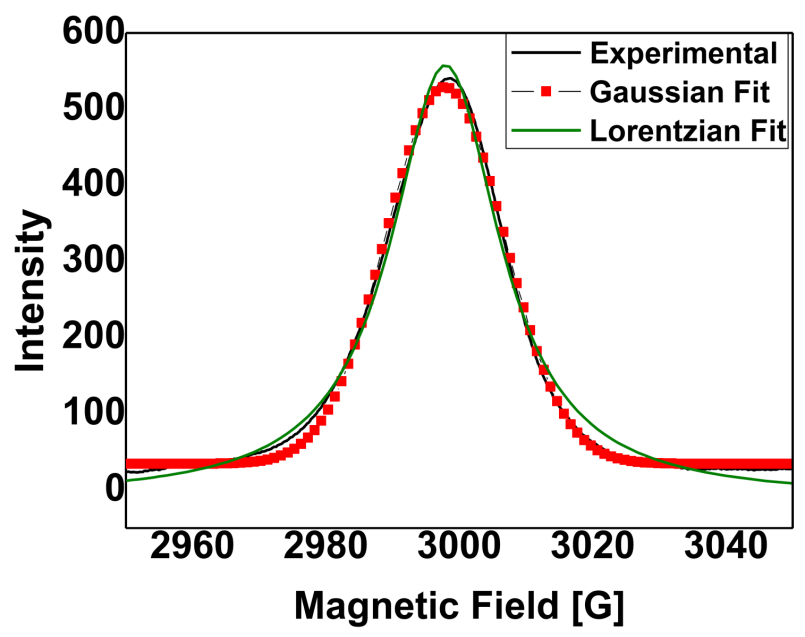

Fig. 10. Gaussian and Lorentzian fits of second lowest magnetic field peak of the EPR spectrum of FVLP0 marked by $*$ in Fig. 9 .

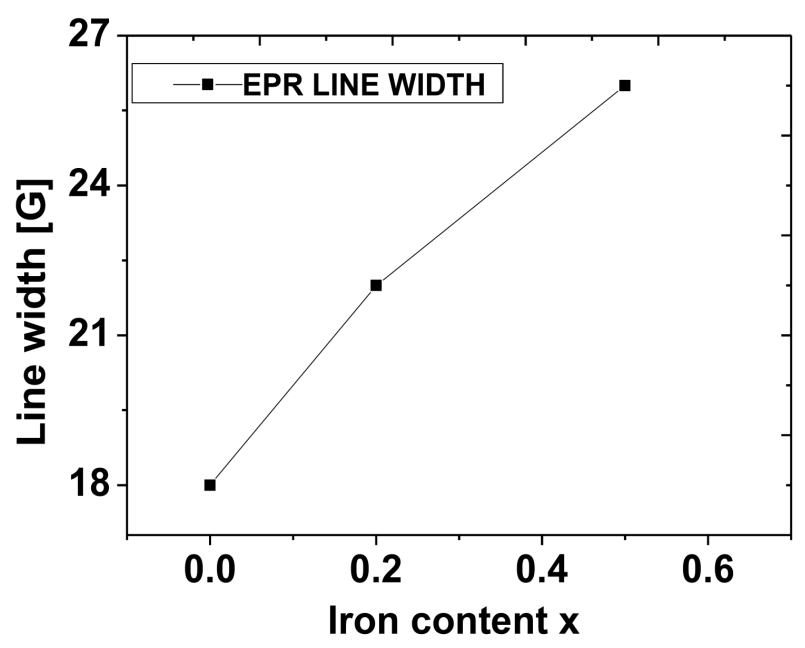

Fig. 11. A comparison of FWHM of EPR in FVLP0, FVLP0.2, and FVLP0.5 glasses.

broadening resulting from the long molecular structure of the porphyrin complex. Saetova et al. could observe well resolved EPR spectrum of vanadyl in the glasses having a very high mol.\% ( $\approx 30 \mathrm{~mol} . \%)$ of vanadium and argued that most of the vanadium is in the diamagnetic $\mathrm{V}^{5+}$ oxidation state [30]. The reduced dipolar and magnetic exchange broadening in FLVP0 may be explained by accepting the presence of non-magnetic $\mathrm{V}^{5+}$ ions so that $\mathrm{V}^{4+}$ is in minority such that the glass behaves as a dilute magnetic system. This is equivalent to the presence of EPR sensitive probe $\mathrm{V}^{4+}$ in a diamagnetic host. This is in agreement with the magnetization results on the FVLP0 sample discussed earlier. The most important line broadening mechanisms in EPR are dipolar and exchange interactions [32, 33]. The magnetic exchange interactions between like spins cause a narrowing of the EPR lines whereas the magnetic exchange interactions between unlike spins cause a broadening of the EPR lines. However, magnetic dipole interaction always causes a broadening of the EPR signals. It is well known that the second lowest field EPR line of the vanadyl spectra in powders and glasses can be used to determine the line width of the EPR spectra by fitting it to Lorentzian/Gaussian shape [31, 34].

To estimate the effect of line broadening on the EPR of vanadyl due to the presence of iron ions along with vanadium we have analysed the full width at half maximum (FWHM) of the second lowest magnetic field EPR signal (at $\approx 300 \mathrm{mT}$ and marked by an $*$ in Fig. 9 ) by fitting it to Lorentzian and/or Gaussian line shape (see Fig. 10 for FVLP0) and the variation is shown in Fig. 11 for three selected glasses (viz. FVLP0, FVLP0.2 and FVLP0.5). It is clear that the FWHM is progressively increasing due to the increase of iron concentration in conformation with the magnetic exchange effect between unlike spins $\mathrm{V}^{4+}$ and $\mathrm{Fe}^{n+}$. FWHM measurements could not be performed for other glasses due to the serious deformation/overlap of the vanadyl EPR spectrum by the $\mathrm{Fe}^{n+}$ EPR spectrum. In turn, it is demonstrated that the intensity of vanadyl EPR is progressively decreasing and the hyperfine structure is smearing out upon replacing vanadium by iron in the glasses. This is expected due to the magnetic exchange interactions as discussed above and the progressive decrease of the vanadium concentration.

\subsection{Spin Hamiltonian parameters}

The EPR spectrum of the vanadyl ion in glasses is analysed by using a spin-Hamiltonian [7-9, 16, 31, 32]:

$$
H=\sum_{i=x, y, z} \beta g_{i} B_{i} S_{i}+A_{i} S_{i} I_{i}
$$

where the first term represents the electronic Zeeman term and the second term represents the nuclear hyperfine interaction with electron spin. The components of the external applied magnetic field vector denotes $B_{i}$, while the other symbols represent their usual meanings.

In an axial symmetry $\left(C_{4 v}\right)$ the $g$ tensor has principal components: $g_{z}=g_{\|}$and $g_{x}=g_{y}=g_{\perp}$. Similarly the hyperfine splitting tensor $A$ has the principal components: $A_{z}=A_{\|}$and $A_{x}=A_{y}=A_{\perp}$. The resonance magnetic fields are given by $[7,20]$ :

$$
\begin{aligned}
& B_{m}=B_{0}-m K \\
& -\frac{A_{\perp}^{2} g_{\perp}^{2}}{4 B_{0} g^{2}}\left(\frac{A_{\|}^{2} g_{\|}^{2}+K^{2} g^{2}}{K^{2} g^{2}}\right)\left[I(I+1)-m^{2}\right] \\
& -\frac{m^{2}}{2 B_{0}}\left(\frac{A_{\|}^{2} g_{\|}^{2}-A_{\perp}^{2} g_{\perp}^{2}}{K g^{2}}\right)^{2}\left(\frac{g_{\|} g_{\perp}}{g^{2}}\right)^{2} \sin ^{2}(\theta) \cos ^{2}(\theta),
\end{aligned}
$$

where $B_{0}=h \nu / g \beta$ with $h$ being the Planck constant, $\beta$ - the Bohr magneton, and $\nu[\mathrm{Hz}]$ - the EPR spectrometer's operating frequency, $m$ assumes eight values: $-7 / 2,-5 / 2, \ldots, 5 / 2,7 / 2$ when $I=7 / 2$, and $\theta$ is the angle between the external applied magnetic field and the principal $z$-axes of $g$ and $A$ tensors which are coincident 
The EPR SHPs of vanadyl ion in the FVLP0.0, FVLP0.2 and FVLP0.5 glasses. The uncertainty in the values of $g$ is \pm 0.001 and in the values of $A$ is \pm 5 [G].

\begin{tabular}{c|c|c|c|c|c|c|c|c}
\hline \hline Sample & $g_{\|}^{*}$ & $g_{\perp}$ & $A_{\|}[\mathrm{G}]$ & $A_{\perp}[\mathrm{G}]$ & $g_{o}$ & $A_{0}[\mathrm{G}]$ & $\delta_{g}$ & $\delta_{A}$ \\
\hline FVLP0.0 & 1.921 & 1.981 & 204. & 78 & 1.961 & 120 & 0.03 & 1.05 \\
FVLP0.2 & 1.920 & 1.980 & 205 & 77 & 1.960 & 120 & 0.03 & 1.06 \\
FVLP0.5 & 1.922 & 1.980 & 203 & 77 & 1.960 & 119 & 0.03 & 1.06
\end{tabular}

with each other for vanadyl ion and coincides with the $\mathrm{V}=\mathrm{O}$ bond direction for the vanadyl complexes. Further the following relations are used:

$$
\begin{aligned}
& K^{2}=A_{\|}^{2} \cos ^{2}(\theta)+A_{\perp}^{2} \sin ^{2}(\theta), \\
& g^{2}=g_{\|}^{2} \cos ^{2}(\theta)+g_{\perp}^{2} \sin ^{2}(\theta), \\
& K^{2} g^{2}=A_{\|}^{2} g_{\|}^{2} \cos ^{2}(\theta)+A_{\perp}^{2} g_{\perp}^{2} \sin ^{2} \theta .
\end{aligned}
$$

Since there is a random distribution of $\mathrm{V}=\mathrm{O}$ bond directions in the glassy structure akin to the powdered crystal (polycrystalline sample) containing vanadyl ions, the EPR spectra of vanadyl ions in glasses are similar in nature to the powder spectra [20]. The resultant EPR spectra are characterized by sixteen resonance signals corresponding to the two so-called turning points [7, 20]: (i) $\theta=0^{\circ}$, i.e., $B$ parallel to the $\mathrm{V}=\mathrm{O}$ bonds (the socalled parallel part of the spectrum), and (ii) $\theta=90^{\circ}$, i.e., $B$ perpendicular to the $\mathrm{V}=\mathrm{O}$ bonds (the so-called perpendicular part of the spectrum) as shown in Fig. 9 and Fig. 10. The calculated spin Hamiltonian parameters (SHP) are collated in Table III.

To justify the correctness of the calculated SHPs the simulated so-called parallel and perpendicular EPR spectra are combined with the observed EPR spectrum of FVLP0 glass in Fig. 12a. The simulated spectra show a good agreement of both $B_{\perp}(m)$ and $B_{\|}(m)$ with the experiment. Also the powder-like EPR spectrum was simulated for FVLP0 to compare with the experimental EPR spectrum. These spectra are shown in Fig. 12b.

Reasonably good agreement between the simulated and observed spectrum is seen which justifies the accuracy of the analysis. However, it may be mentioned here that in contrast to the polycrystalline (powder) sample in the case of strongly disordered systems like glasses a wide distribution of $g$ and $A$ parameters may take place by nature and this would cause diffuse effect on the averaged resultant EPR spectrum. Meaningful analysis of vanadyl EPR spectra could only be done for FVLP0, FVLP0.2 and FVLP0.5 glasses because in other glasses the vanadyl EPR spectra overlapped with the iron EPR spectra and smeared out too much to be analysed properly. It may be discussed here that for perfect octahedral symmetry one expects isotropic values of $g$ and $A$ parameters defined as:

$$
g_{\mathrm{o}}=\frac{1}{3}\left(g_{x}+g_{y}+g_{z}\right) \rightarrow \frac{1}{3}\left(g_{\|}+2 g_{\perp}\right),
$$

and

$$
A_{0}=\frac{1}{3}\left(A_{x}+A_{y}+A_{z}\right) \rightarrow \frac{1}{3}\left(A_{\|}+A_{\perp}\right) .
$$

Due to distinct $\mathrm{V}=\mathrm{O}$ bond vanadyl complexes are always tetragonally compressed to a lesser or greater extent. Hence, $g_{\|}<g_{\perp}<g_{e}=2.003$ and $A_{\|}>A_{\perp}$ are always observed [17]. The tetragonal compression of the $\left[(\mathrm{V}=\mathrm{O}) \mathrm{O}_{5}\right]$ octahedra may be compared with the help of the out-of-plane anisotropies of the $g$ and $A$ parameters defined by $\delta_{g}$ and $\delta_{A}$, respectively:

$$
\delta_{g}=\frac{\left|g_{\|}-g_{\perp}\right|}{g_{\mathrm{o}}} \text { and } \delta_{A}=\frac{\left|A_{\|}-A_{\perp}\right|}{A_{0}} .
$$

These parameters are included in Table III along with other SHPs. For no distortion of the regular octahedral coordination these anisotropy parameters reduce to zero. It is clear from the values of anisotropy parameters that the tetragonal compression does exist but remains essentially unaltered by the concentration of vanadium up to $2 \mathrm{~mol} . \%$ in the glasses under discussion.

\subsection{Bonding parameters for vanadyl complexes}

For the purpose of approximate estimation of bonding parameters of the local vanadyl complexes, the following simplified expressions appropriate to $C_{4 v}$ symmetry of the vanadyl complexes may be used [20, 29, 30]:

$$
\begin{aligned}
\Delta g_{\|} & =8\left(\beta_{1}^{*} \beta_{2}^{*}\right)^{2} \lambda / \Delta E_{\|} \\
\Delta g_{\perp} & =2\left(\beta_{2}^{*} e^{*}\right)^{2} \lambda / \Delta E_{\perp} \\
-\frac{A_{\|}}{P} & =\left(\beta_{2}^{*}\right)^{2}\left(k+\frac{4}{7}\right)+\Delta g_{\|}+\frac{3}{7} \Delta g_{\perp}, \\
-\frac{A_{\perp}}{P} & =\left(\beta_{2}^{*}\right)^{2}\left(k-\frac{2}{7}\right)+\frac{11}{14} \Delta g_{\perp} .
\end{aligned}
$$

where $\Delta g_{\perp,(\|)}=g_{\mathrm{e}}-g_{\perp,(\|)}$, and $g_{\mathrm{e}}$ is the free electronic $g$ value $(g=2.0023), \beta_{1}^{*}, \beta_{2}^{*}$ and $e_{\pi}^{*}$ are the molecular orbital (MO) bonding parameters, $\Delta E_{\perp,(\|)}$ are the energy splitting of the corresponding orbitals of vanadyl complex $P=g_{\mathrm{e}} g_{N} \beta \beta_{N}<r^{-3}$, and $k$ are the dipolar-coupling-parameter and the Fermi-contactparameter, respectively, for vanadium $\left(\mathrm{V}^{4+}\right)$ nucleus and $\lambda$ is the spin-orbit-coupling constant of the metal ion $\left(\mathrm{V}^{4+}\right)$. The corresponding electronic energy splittings $\Delta E_{\perp,(\|)}$ are obtained from the optical absorption spectrum. The parameters $\beta_{1}^{*}$ and $\beta_{2}^{*}$ measure the in-plane $\sigma-$ and $\pi-$ bonding respectively and $e_{\pi}^{*}$ measures the out-of-plane $\pi$-bonding. Here an octahedral vanadyl complex $\left[(\mathrm{V}=\mathrm{O}) \mathrm{O}_{5}\right]$ is assumed with tetragonal (axial) contraction along axial $\mathrm{V}=\mathrm{O}$. Four out of the five bonding oxygens are treated coplanar with metal ion and are called the equatorial oxygens. The vanadyl oxygen and the sixth oxygen are called apical/(axial). 


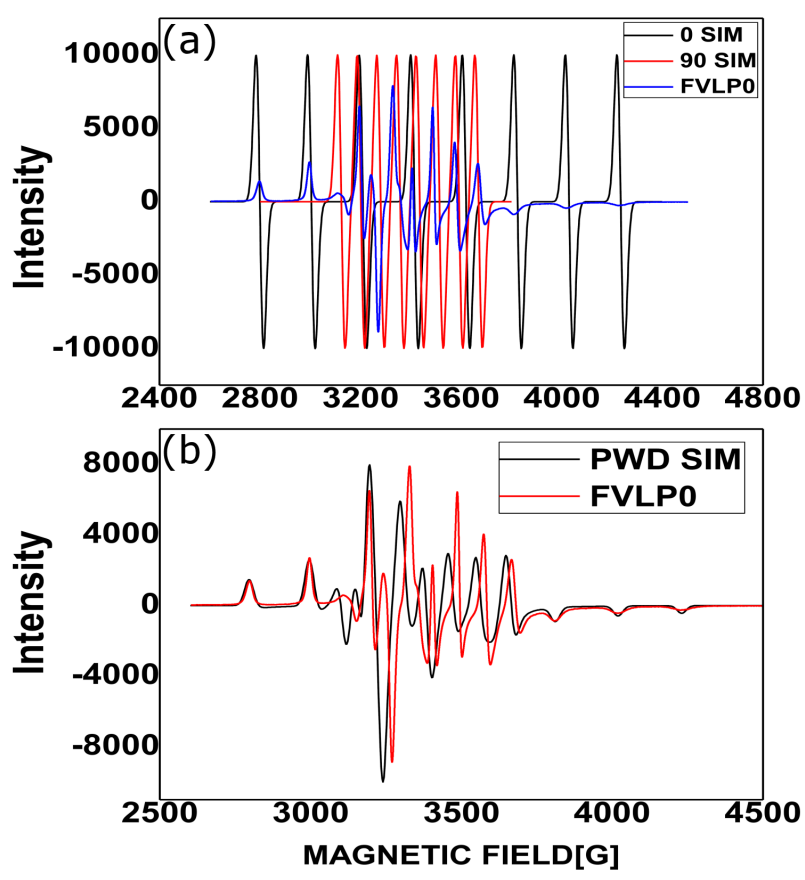

Fig. 12. (a) Overlapped EPR spectra of FVLP0 glass. OSIM and 90SIM represent the simulated parallel and perpendicular parts, respectively. Spectrum FVLP0 is the experimental EPR spectrum of the iron free FVLP0 glass. (b) Simulated powder-like EPR spectrum of FVLP0 glass (PWD-SIM). The observed EPR spectrum (FVLP0) is also given for a comparison.

Therefore in-plane means within the equatorial plane $\mathrm{V}-\mathrm{O}_{4}$. Out-of-plane means perpendicular to the equatorial plane, i.e., along the apical axis. With oxygen as ligands it is assumed that the in-plane $\pi$-bonding parameter $\beta_{2}^{*}=1$ [17]. From the SHPs and the orbital energies $\Delta E_{\perp,(\|)}$ the dipolar hyperfine coupling parameter $P=2 \gamma \beta \beta_{N}\left(r^{-3}\right)$, the Fermi contact parameter $k$ and the bonding parameters $\beta_{1}^{*} \beta_{2}^{*}, e_{\pi}^{*}$ may be evaluated using the above expressions. The value of $\lambda=170 \mathrm{~cm}^{-1}$ for vanadium is taken here for calculations. The bonding parameter $\left(\beta_{2}^{*}\right)^{2}$ is usually found to be very close to unity for the octahedral vanadyl species with oxygen as ligands hence it becomes easier to determine four unknowns: $\left(\beta_{2}^{*}\right)^{2}$, $\left.e_{\pi}^{*}\right)^{2}, P$ and $k$ provided energies $\Delta E_{\perp,(\|)}$ are known. For reasonable estimates of the parameters $\Delta E_{\perp}=1.2$ and $\Delta E_{\|}=1.6$ in units of $10^{4} \mathrm{~cm}^{-1}$ which are assumed here [20]. An estimate of $k=0.84$ and $P \approx 135 \mathrm{G}$ is made from the above relations for $A_{\perp}$ and $A_{\perp}$ and SHPs given in Table IV. The parameter $k$ is sensitive to the $4 s$ character in the orbitals and higher the value $k$ higher is the contribution of the unpaired $s$ electron to the hyperfine splitting. The theoretical value of $P$ obtained by Watson with the help of Hartee-Fock radial function of $\mathrm{V}^{4+}$ ion is $160 \times 10^{-4} \mathrm{~cm}^{-1}(\approx 171 \mathrm{G})$ [35]. The lower value obtained here may be attributed to the covalent bonding of the $\mathrm{V}^{4+}$ ion with the ligands. For vanadyl complexes $P$ is found to lie between $(100-160) \times 10^{-4} \mathrm{~cm}^{-1}$, i.e., $\approx(107-171) \mathrm{G}$. The values of $k$ and $P$ obtained here
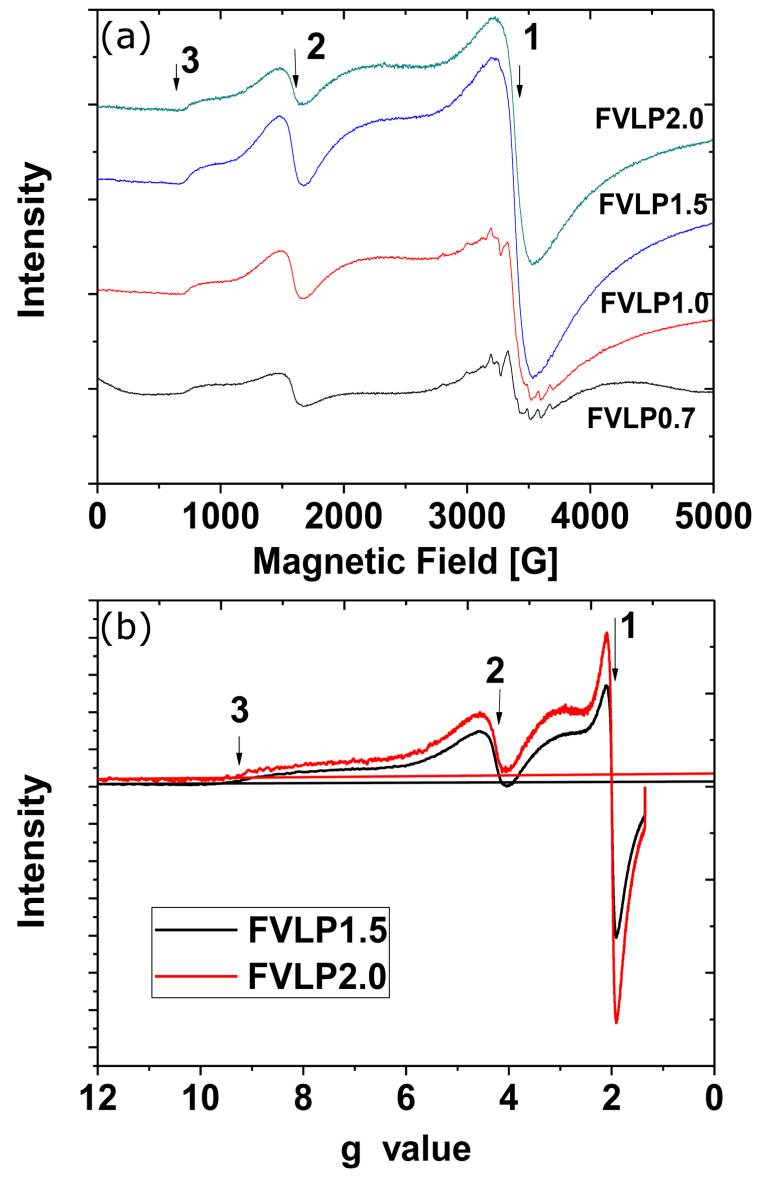

Fig. 13. (a) EPR spectra of FVLP0.7, FVLP1.0, FVLP1.5 and FVLP2.0 glasses at RT and at X-band. (b) Frequency independent EPR spectra of FVLP1.5 and FVLP2.0 glasses.

compare favourably well with those measured for vanadyl complexes [20]. The excitation energies $\Delta E_{\|}=E_{b 1}-E_{b 2}$ and $\Delta E_{\perp}=E_{\text {eg }}-E_{b 2}$ are assumed here with $b_{2}$ to be the ground state orbital of the vanadyl complex with $C_{4 v}$ symmetry $[20,29,30]$. The product $k \cdot P$ provides the isotropic hyperfine interaction parameter which in this case is $\approx 115 \mathrm{G}$ which is slightly less than the experimental isotropic hyperfine parameter $A_{0}=\approx 120 \mathrm{G}$, and which may be assigned to the co-valency effects in the bonding. Assuming $k$ to be anisotropic with principal components: $k_{\|}$and $k_{\perp}$ we can find them from the relations: $k_{\|}=P / A_{\|}$and $k_{\perp}=P / A_{\perp}$. The calculated values of $k_{\|}$and $k_{\perp}$ are given in Table IV along with other parameters.

To have a better visualization of the features the EPR spectra of the second group (viz. glasses FVLP0.7, FVLP1.0, FVLP1.5 and FVLP2.0) are separately shown in Fig. 13a.

It would be easier to understand if we first discuss the EPR spectrum of FVLP2.0 because the sample is free from vanadium hence the spectrum is free from any overlapping of iron and vanadium EPR spectra. All the resonance peaks in this EPR spectrum are assigned purely 
$P, k$, and other bonding parameters for the vanadyl octahedral units in the glasses.

TABLE IV

\begin{tabular}{c|c|c|c|c|c|c|c|c|c}
\hline \hline Sample & $P[\mathrm{G}]$ & $k$ & $k_{\|}$ & $k_{\perp}$ & $P \cdot k[\mathrm{G}]$ & $\left(\beta_{1}^{*}\right)^{2}$ & $\left(e_{\pi}^{*}\right)^{2}$ & $1-\left(\beta_{2}^{*}\right)^{2}$ & $1-\left(e_{\pi}^{*}\right)^{2}$ \\
\hline FVLP0.0 & 135. & 0.85 & 0.66 & 1.73 & 115 & 0.94 & 0.50 & 0.06 & 0.50 \\
FVLP0.2 & 137 & 0.83 & 0.66 & 1.75 & 114 & 0.96 & 0.60 & 0.04 & 0.40 \\
FVLP0.5 & 135 & 0.85 & 0.67 & 1.75 & 114 & 0.93 & 0.56 & 0.07 & 0.44
\end{tabular}

EPR signal characteristics of FVLP $x$ glasses $(x=0.7,1.0,1.5$ and 2.0).

TABLE V

\begin{tabular}{c|c|c|c|c|c|c}
\hline \hline Sample parameter & FVLP0.2 & FVLP0.5 & FVLP0.7 & FVLP1.0 & FVLP1.5 & FVLP2.0 \\
\hline resonance peak position & $2^{a}(-)$ & $2(-)$ & $2(420)$ & $2(400)$ & $2(380)$ & $2\left(340^{c}\right)$ \\
in terms of $g$ & $4.3^{a}(245)$ & $4.3(245)$ & $4.3(240)$ & $4.3(230)$ & $4.3(210)$ & $4.3\left(200^{d}\right)$ \\
$\left(\Delta B_{\mathrm{p}-\mathrm{p}}\right.$ line width [G] $)$ & $9.3^{b}(-)$ & $9.3(-)$ & $9.3(-)$ & $9.3(-)$ & $9.3(-)$ & $9.3(-)$ \\
\hline $\begin{array}{c}\text { relative intensity of } \\
\left(I_{g=2} / I_{g=4.3}\right)\end{array}$ & - & - & 4 & 11 & \multirow{2}{*}{15} & 19 \\
\hline
\end{tabular}

The error in $\mathrm{g}$ is ${ }^{a} 0.1$ and ${ }^{b} 0.3$, the error in line width is ${ }^{c} 25 \mathrm{G}$ and ${ }^{d} 15 \mathrm{G}$.

to iron. It is clear from the spectrum that there are three distinct resonance signals of different intensity and line width and they are marked as 1, 2 and 3 in order of decreasing magnetic field in Fig. 13a. Instead of magnetic field the EPR signals may also be characterised by $a$ parameter $g$ which is independent of the EPR spectrometer's operating frequency. The frequency independent variable $q$ is defined as: $g=h \nu / \beta B_{\text {reson, where }} B_{\text {reson }}$ is the resonance field, i.e. the centre of the resonance peak in terms of the applied external magnetic field. The EPR spectra of glass FVLP1.5 and FVLP2.0 are shown in Fig. 13b in terms of the variable $g$ for comparison and discussion. The presentation of EPR spectra in terms of $g$ is advantageous because it remains unaltered even if the experiments are done at multi frequencies. It may be mentioned here that the EPR signals of vanadyl have diminished to almost negligible levels in these samples and the features of the EPR signals of iron are vividly seen.

The characteristics of the EPR spectra are summarized in Table V. Iron is one of the most pervasive impurities in borate and phosphate glasses. Iron can exist in $\mathrm{Fe}^{2+}$ and/or $\mathrm{Fe}^{3+}$ oxidation states in glasses. $\mathrm{Fe}^{2+}$ is EPR silent at $\mathrm{RT}$ but $\mathrm{Fe}^{3+}$ gives EPR signals over a very wide range of temperature $[13,36]$. The ferric ion $\left(d^{5}\right)$ in the absence of external magnetic field has three Kramers doublets which split into six levels in an external magnetic field corresponding to $M_{S}$ value from $+5 / 2$ to $-5 / 2$ and its EPR spectrum is expected to show five resonance signals according to allowed transitions $\Delta M_{S}= \pm 1[7,8,30]$. Rao and Rao [37] studied the EPR of transition metal ions including iron in glasses and found typical EPR spectra of iron in glasses.

The features of EPR spectra of $\mathrm{Fe}^{3+}$ in glasses were successfully explained by Castner et al. [38] by using the spin Hamiltonian given below [7, 9, 10, 39, 40] :

$H=g \beta \boldsymbol{B} \cdot \boldsymbol{S}+D\left[S_{z}^{2}+\frac{S(S+1)}{3}\right]+E\left[S_{x}^{2}-S_{y}^{2}\right]$, where $D$ and $E$ are called the axial and tetragonal zero field splitting (ZFS) parameters respectively, $S_{i}(i=x, y, z)$ denotes the components of electron spin $\boldsymbol{S}$. Being an $S$-state ion $\mathrm{Fe}^{3+}$ has an isotropic $g$ $\left(g_{x}=g_{y}=g_{z}=2\right.$ (the free electronic value)) tensor but $D$ and $E$ depend on the local environment of $\mathrm{Fe}^{3+}$ ion and consequently may be highly anisotropic. In regular octahedral local ligand field both $D=E=0$ and the EPR spectrum comprises a closely spaced quintet (set of five fine splitting EPR signals) at $g=2$ [7-9]. This quintet becomes a single broad line under the influence of dipolar broadening in systems having a higher concentration of iron and also at elevated temperatures due to motional narrowing $[13,32,33,40]$. In local fields of lower symmetry (rhombic, tetragonal, tetrahedral etc.) with distortion the energy levels of $\mathrm{Fe}^{3+}$ in an external magnetic field become complicated if external magnetic field $B$ is not along the principal axes and the ZFS parameters are large $[39,40]$. In a tetragonal local symmetry $E=0$ and if $D \gg h \nu$ only transitions between the $| \pm 1 / 2\rangle$ energy states will be observed at $g=2=g_{\|}$ for $\boldsymbol{B}$ parallel to $z$-axis of the ZFS tensor but for $B_{\perp}$ to the $z$-axis of ZFS tensor the resonance signal will be observed at $g \approx g_{\perp} \approx 6[7,9,10]$. Mc Gavin and Tennant [40] in their excellent paper have explained in detail the occurrence of an isotropic $g$-tensor in high spin $d^{5}$ systems under various conditions for $D$ and $E$. Some specific features of the $\mathrm{Fe}^{3+}$ EPR line width and shape in glass networks depend on the glass composition and the concentration of paramagnetic ions. The EPR spectra of most glasses containing iron exhibit the two well known resonances at the effective $g$ values $\left(g_{\text {eff }} \approx 2\right.$ and $\left.g_{\text {eff }} \approx 30 / 7\right)$ that have been considered as a signature of the presence of $\mathrm{Fe}^{3+}$ ions in a glassy host [41]. The $\mathrm{X}$-band EPR spectra (frequency $\approx 9 \mathrm{GHz}$ ) of most oxide glasses with low $\mathrm{Fe}^{3+}$ concentrations show an EPR signal at $g_{\text {eff }}=30 / 7$ which is relatively narrow as compared to the EPR signal at $g_{\text {eff }}=2$. The sharpness of this signal may be assigned to the isotropic nature and lesser effect 

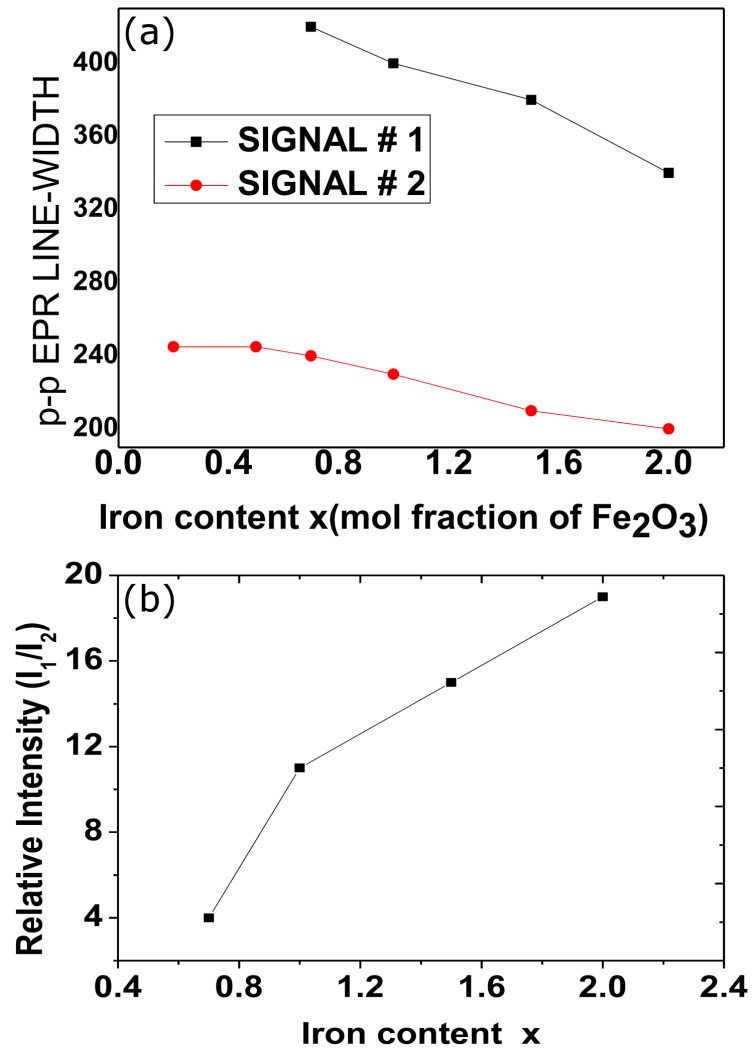

Fig. 14. (a) Variation of peak-to-peak EPR line width of signals marked $1 \& 2$ in Fig. 13. (b) Relative intensity of signal 1 to signal 2 .

of the $g$-strain (distribution of $g$ in disordered glasses) on this signal. The observation of an intense isotropic signal at $g \approx 30 / 7$ and a weak signal at $g \approx 9$ may generally be taken to be indicative of high spin $\mathrm{Fe}^{3+}$ in a rhombic environment where $D= \pm 3 E$. It has been discussed by Golding et al. [39] that both tetragonal and rhombic distortions from octahedral symmetry may give $g \approx 30 / 7$ isotropic signal under different conditions.

The main features of the observed EPR signals of $\mathrm{Fe}^{3+}$ in the glasses under study may be summarized here:

1. The positions of EPR signals ( $g$ values) are unaltered within the experimental errors for all the FVLP $x$ glasses under study.

2. The $g \approx 9$ signal (called signal 3 ) is the weakest signal and its relative intensity does not appear to increase with the increase of iron concentration proportionally.

3. The relative intensities of $g=4.3$ (called signal 2) and $g=2$ (called signal 1) increase progressively as the iron content is increased but the increase is not linearly proportional as revealed by the intensity ratio plotted in Fig. 14b.

4. The $p$ - $p$ line widths of both signal 1 , as well as signal 2 progressively decrease upon increasing the iron content $x$.
Bogomolova and Henner [42] showed how at X-band the $g_{\text {eff }} \approx 2$ line width can be explained by a clustering of $\mathrm{Fe}^{3+}$ ions. The theory predicts an increase of line width with spin concentration due to the dipolar broadening [32, 33]. The exchange interaction between like spins will cause line narrowing [33]. However, exchange interaction is believed to appear at a sufficiently high concentration of paramagnetic ions when neighbouring spins become highly coupled. The $g=4.3$ resonance can be produced by rhombic symmetry $D=3 E$ of either octahedral or tetrahedral coordination of $\mathrm{Fe}^{3+}$ with effective tetragonal distortion $\left(C_{4 v}\right)$. Different possible coordination environments of iron can cause different values of $D$ and $E$ which are associated with resonances at $g=2$, $4.3,6$, and 9 [36-42]. In the case of strongly disordered systems (for example glasses) wide distribution of $D$ and $E$ values may take place in the same host. As a result, broad diffuse absorption from zero field to higher magnetic fields occurs with the lines corresponding to the singularities, i.e., at $g=9.7,4.3,3.3,6.0$ and 2.0 [40]. For the polycrystalline substances the situation is however, different because local environment of the $\mathrm{Fe}^{3+}$ ions is well defined. The $g=2.0$ resonance can be caused by both axiality of the crystal field $(E=0)$ and spin-spin interaction. Momo et al. showed that the $g=4.3$ resonance is due to $\mathrm{Fe}^{3+}$ ions in rhombic sites in their studies of selected silicate glasses [36]. Iwamoto et al. [41] have investigated the state of $\mathrm{Fe}^{3+}$ ion and $\mathrm{Fe}^{3+}-\mathrm{F}^{-}$interaction in $x \mathrm{CaF}_{2}-9(1-x) \mathrm{CaO}-9 \mathrm{SiO}_{2}(0<x<0.3)$ glasses by ESR and only two resonances were observed near $g=2.0$ and $g=4.3$ which were assigned to $\mathrm{Fe}^{3+}$ ions with dipole-dipole interactions and isolated $\mathrm{Fe}^{3+}$ ions in rhombic symmetry, respectively. In the light of the above discussion the following inferences could be made in the present study:

1. The $g=2$ signals represent the nearly regular octahedral coordination of oxygens with the metal ion $(D=E=0)$. The magnetic dipole exchange narrowing effects dominate over the dipolar broadening up to the $2 \%$ concentration of iron in the glasses under study, hence the line width of the EPR signal is seen decreasing progressively. Since the relative intensity of the $g=2$ signal is the highest as compared to $g=4.3$ and $g \approx 9$ signals, the regular octahedral co-ordination is in majority as compared to other coordinations discussed below.

2 . The $g=4.3$ signal represents the strong rhombic distortion $(D=3 E)$ in the metal ion coordination and a resulting large ZFS is responsible for an isotropic $g=4.3$ transition. The variation of relative intensities (Fig. 14b) of $g=2$ and $g=4.3$ indicates the increase in the concentrations of both the octahedral co-ordination and tetragonal co-ordination but the former increases more rapidly.

3. The weak $g \approx 9$ signal does not represent to any specific co-ordination but is often observed in the powder/glass spectra of the completely rhombic 
$\mathrm{Fe}^{3+}$ systems $(D=3 E)$ in addition to the intense isotropic $g=4.3$ signal. Nevertheless the observation of an intense isotropic $g=4.3$ signal and a weak $g \approx 9$ may generally be taken to be indicative of high spin $\mathrm{Fe}^{3+}$ in nearly complete rhombic environment [39, 43].

\section{Conclusion}

The samples FVLP $x(x=0,0.2,0.5,0.7,1.0,1.1$, and 2.0) prepared by quick melt quenching have shown their glassy nature when studied by XRD. The density measurements have shown that the density increases progressively as $\mathrm{V}$ is replaced by $\mathrm{Fe}$ (i.e. $x$ is increased from 0 to 2.0). The reason is assigned to a better atomic filling and replacement by a heavier metal Fe. The molar volume is found to decrease as $x$ is increased whereas the theoretical optical basicity remains almost same in these glasses. The IR absorption bands reveal the presence of various structures involving $\mathrm{P}$ and $\mathrm{O}$ such as: $\mathrm{P}=\mathrm{O}$, $\mathrm{O}-\mathrm{P}-\mathrm{O}^{-},(\mathrm{P}-\mathrm{O}-\mathrm{P})$, and $\mathrm{O}-\mathrm{P}-\mathrm{O}$ groups as revealed by the characteristic vibrations. The presence of $\mathrm{V}$ and $\mathrm{Fe}$ in the range of $0-2$ mol. $\%$ does not seem to cause appreciable structural changes to be reflected in IR spectra in these phosphate glass systems. The experimental magnetic moment per fu is in consistence with the calculated magnetic moment per fu. This discrepancy can be explained if the canted-antiferromagnetic pairing of the magnetic ions is envisaged. The EPR study reveals that vanadium exists in the form of vanadyl local complexes and there is a considerable covalence in the bonding. However, the presence of $\mathrm{V}^{5+}$ is also suggested based on the magnetization results. Iron gives three EPR signals at $g=2, g=4.3$ and $g \approx 9$ which are assigned to two coordinations of ferric ion with oxygen viz. octahedral and nearly complete rhombic. However, neither the presence nor the absence of $\mathrm{Fe}^{2+}$ could be confirmed by the experiments done in the present study.

\section{Acknowledgments}

The authors are thankful to (i) the CIL, DCRUST for their facilities to synthesize the glasses and to do FTIR, XRD, and density measurements, (ii) SAIF, IIT, Madras for their facilities to do VSM and EPR measurements.

\section{References}

[1] N.P. Bansal, R.H. Doremus, Handbook of Glass Properties, Academic Press (Indian Reprint), 2006.

[2] D. Dorosz, J. Zmojda, M. Kochanowicz, J. Dorosz, Acta Phys. Pol. A 118, 1108 (2010).

[3] G. Kaur, O.P. Pandey, K. Singh, D. Homa, B. Scott, G. Pickrell, J. Biomed. Mater. Res. A 102A, 254 (2014).

[4] R.K. Brow, J. Non-Cryst. Solids 263, 1 (2000).

[5] M. Karabulut, E. Melnik, R. Stefan, G.K. Marasinghe, C.S. Ray, C.R. Kurkjian, D.E. Day, J. NonCryst. Solids 288, 8 (2001).
[6] J.A. Weil, J.R. Bolton, J.E. Wertz, Electron Paramagnetic Resonance, Wiley, New York 1994.

[7] Handbook of Electron Spin Resonance, Eds. C.P. Poole, H.A. Farach, AIP Press, New York 1994.

[8] C.A. Carrington, A.D. Carrington, Introduction to Magnetic Resonance, Chapman and Hall, 1979.

[9] D.L. Griscom, J. Non-Cryst. Solids 40, 211 (1980).

[10] R.S. Drago, Physical Methods in Inorganic Chemistry Reinhold Publ. Co., New York 1965, Chs. 10 and 11.

[11] D. Jiles, Introduction to Magnetism and Magnetic Materials, 3rd ed., CRC Press, 2015.

[12] P. Chand, R.C. Srivastava, A. Upadhyay, J. Alloys Compd. 460, 108 (2008).

[13] J. Ashkin, N.S. Vanderven, Physica C 95B, 1 (1978).

[14] G.L. Mc Pheron, R.C. Koch, G.D. Stucky, J. Chem. Phys. 60, 1424 (1974).

[15] J. Krzystek, A.T. Fiedler, J.J. Sokol, A. Ozarowski, S.A. Zvyagin, T.C. Brunold, J.R. Long, L.-C. Brunel, J. Telser, Inorg. Chem. 43, 5645 (2004).

[16] Prem Chand, V.K. Jain, G.C. Upreti, Magn. Reson. Rev. 14, 49 (1988).

[17] G.C. Upreti, P. Chand, Magn. Reson. Rev. 12, 245 (1987).

[18] J.E. Garbarczyk, M. Wasiucionek, P. Jóźwiak, L. Tykarski, J.L. Nowiński, Solid State Ion. 154-155, 367 (2002).

[19] T.K. Pietrzak, P.P. Michalski, P.E. Kruk, W. Ślubowska, K. Szlachta, P. Duda, J.L. Nowiński, M. Wasiucionek, J.E. Garbarczyk, Solid State Ion. 302, 45 (2017)

[20] P. Chand, L. Kumar, A. Yadav, S. Khasa, Acta Phys. Pol. A 136, 897 (2019).

[21] J. Duffy, M. Ingram, J. Am. Chem. Soc. 93, 6448 (1971).

[22] J. Van Wazer, Phosporus and Its Compounds, Vols. 1 and 2, Interscience, New York 1951.

[23] Y.M. Moustafa, K. El-Egili, J. Non-Cryst. Solids 240, 144 (1998).

[24] U. Hoppe, J. Non-Cryst. Solids 195, 138 (1996).

[25] Y.B. Saddeek, Physica B 406, 562 (2011).

[26] A. Mekki, G.D. Khattak, D. Holland, M. Chinkhota, L.E. Wenger, J. Non-Cryst. Solids 318, 193 (2003).

[27] S. Saetova, A.A. Raskovalov, B.D. Antonov, T.V. Yaroslavtseva, O.G. Reznitskikh, E.V. Zabolotskaya, N.I. Kadyrova, A.A. Telyatnikova, Ionics $\mathbf{2 4}$, 1929 (2018)

[28] I. Ardelean, M. Peteanu, S. Filip, V. Simon, I. Todor, Solid State Commun. 105, 339 (1998).

[29] D. Kivelson, S. Lee, J. Chem. Phys. 41, 1896 (1964).

[30] J. Selbin, Coord. Chem. Rev. 1, 293 (1966); J. Selbin, Chem. Rev. 65, 153 (1965).

[31] S. Sharma, A. Kumar, P. Chand, B.K. Sharma, S. Sarkar, Spectrochim. Acta A 63, 556 (2006).

[32] J.H. Van Vleck, Phys. Rev. 74, 1168 (1948).

[33] G.C. Upreti, R.S. Saraswat, Magn. Reson. Rev. 7, 215 (1982).

[34] J.A. Weil, H.G. Hecht, J. Chem. Phys. 38, 281 (1963). 
[35] R.E. Watson, Iron Series Hartee-Fock Calculations, Tech. Rep. No. 12, Solid State and Molecular Theory Group, MIT, (MA) USA 1959.

[36] F. Momo, G.A. Ranieri, A. Sotgiu, J. Non-Cryst. Solids 46, 115 (1981).

[37] K.J. Rao, B.G. Rao, Prec. Indian Acad. Sci. (Chem. Sci.) 95, 169 (1985).

[38] T. Castner, G.S. Newell, W.C. Holton, C.P. Slichter, J. Chem. Phys. 32, 668 (1960).

[39] R.M. Golding, T. Singhasuwich, W.C. Tennant, J. Phys. C Solid State Phys. 11, 5041 (1978).
[40] D.G. Mc Gavin, W.C. Tennant, Mol. Phys. 45, 77 (1982).

[41] N. Iwamoto, Y. Makino, S. Kasahara, J. Non-Cryst. Solids 55, 113 (1983).

[42] L.D. Bogomolova, E.K. Henner, J. Magn. Reson. 41, $422(1980)$.

[43] Mc.D.G. Gavin, W.C. Tennant, J. Magn. Reson. 61, 321 (1985). 